\title{
The Management of Hematologic Patients with Bloodstream Infections Due to Multi-Drug Resistant Bacteria: Where Do We Stand? From Antibacterial Prophylaxis to the Treatment of Septic Shock
}

\author{
Carolina Secreto ${ }^{1,2}$, Alessandro Busca ${ }^{1, *}$, Tommaso Lupia ${ }^{3}$, Silvia Corcione ${ }^{3}$ \\ and Francesco Giuseppe De Rosa ${ }^{3}$ \\ 1 Stem Cell Transplant Center, AOU Citta' Della Salute e Della Scienza, 10100 Turin, Italy; \\ csecreto@cittadellasalute.to.it \\ 2 Department of Hematology, AOU Citta' Della Salute e Della Scienza, 10100 Turin, Italy \\ 3 Department of Medical Sciences, University of Turin, 10100 Turin, Italy; tommaso.lupia89@gmail.com (T.L.); \\ silvia.corcione@unito.it (S.C.); francescogiuseppe.derosa@unito.it (F.G.D.R.) \\ * Correspondence: abusca@cittadellasalute.to.it
}

Received: 15 October 2020; Accepted: 20 November 2020; Published: 25 November 2020

\begin{abstract}
Bloodstream infection (BSI) and septic shock represent one of the major limiting factors for the successful treatment of patients affected by hematologic malignancies. During the most recent years we have documented a shift in the epidemiology of bacterial infections toward a consistent rise of Gram-negative rods. In addition, the emergence of multi-drug-resistant bacteria is considered a life-threatening condition requiring a multi-disciplinary approach. Aim of present review is to summarize the most recent approaches in terms of anti-microbial prophylaxis and treatment of BSI in hematologic patients with neutropenic fever.
\end{abstract}

Keywords: bloodstream infections; multi-drug-resistant bacteria; septic shock

\section{Introduction}

Despite remarkable improvements have been achieved in the management of patients with malignant hematologic disorders, infectious complications still represent a leading cause of morbidity and mortality, particularly during the neutropenic phase after the chemotherapy treatment.

Bloodstream infection (BSI) affects $11 \%$ to $40 \%$ of neutropenic patients, with an associated mortality ranging from $5 \%$ to $60 \%$ in cases of multi-drug-resistant (MDR) organisms BSI [1-5]. The epidemiology of BSI has undergone substantial changes in the most recent years: during the 1990s, Gram-positive BSI were the leading cause of BSI due to the increased use of intravascular devices and the extensive use of prophylaxis with fluoroquinolones (FQ) [6]. This trend was followed by the gradual rise of Gram-negative rods, with extended-spectrum beta-lactamase (ESBL), multi-drug resistance (MDR) and carbapenem-resistant Enterobacteriales (CRE) as well as MDR P. aeruginosa and Acinetobacter spp. as critical issues in daily clinical practice. A recent review by the European Conference on Infections in Leukemia (ECIL) group showed a change of the Gram-positive to Gram-negative ratio to $55-45 \%$ from 60-40\%, reported by studies published between 2005 and 2011 [7].

According to this observation, the potential benefit of fluoroquinolone (FQ) prophylaxis in terms of the reduced rate of BSI needs to be weighted against its impact in terms of increased risk of colonization with MDR strains. Aim of the present review is to summarize the current epidemiology of BSI in patients with hematologic malignancies and hematopoietic stem cell transplant (HSCT) recipients, to provide a critical appraisal of the usefulness of FQ prophylaxis, to review the contemporary 
epidemiological trends and to define the most appropriate antibiotic treatment in febrile neutropenia considering rising anti-microbial resistance.

\subsection{Etiology}

MDR bacteria are increasingly recognized in hematology patients, and the prevalence of different resistant species varies significantly between centers [7-9]. Bacteria have been defined as MDR if they are resistant "to three or more antibiotic classes" or according to other authors, resistant "to one key anti-microbial agent" [10]. The spectrum of MDR bacteria identified in hematologic patients is mostly limited to Gram-negative rods. Traditionally P. aeruginosa infections have been frequently encountered in hematological population and recently its management got complicated by the raising of MDR strains [7-9]. Several European countries did already show an increase in extended-spectrum $\beta$-lactamase (ESBL), with the recent addition of carbapenem-resistant K. pneumoniae, endemic in Italy and Greece, and MDR Acinetobacter baumannii [11]. Within Gram-positive infections, the prevalence is due to methicillin-resistant S. aureus (MRSA) and Enterococci. However, vancomycin-resistant enterococci, especially in HSCT recipients, remain a troublesome and actual nosocomial infection, with significant geographical variability $[7-9,12,13]$. A prospective study from the European Society for Blood and Marrow Transplantation (EBMT) analyzed the emergence of MDR Gram-negative rods during the first six months following HSCT among 65 centers in Europe, Australia, and Asia. Overall, 655 Gram-negative episodes in 591 patients were included in the final analysis: 414 in allogeneic and 241 in autologous hematopoietic stem cell (HSC) recipients. Enterobacteriaceae accounted for $73 \%$ of the bacteremia; non-fermentative rods, for $24 \%$; and others, Gram-negative for 3\% of the episodes. Overall, $50 \%$ of the isolates were FQ and non-carbapenem-resistant, $18.5 \%$ were carbapenem-resistant, and 35\% were MDR. The rate of FQ-resistant (FQ-R) organisms was significantly higher in centers providing prophylaxis (79\% vs. $50 \%$ in allogeneic HSCT and $74 \%$ vs. $25 \%$ in autologous HSCT) and in patients receiving an allogeneic HSCT compared to autologous HSCT ( $56 \%$ vs. $41 \%, p<0.001$ ). Similarly, the rate of MDR isolates was significantly higher in patients receiving FQ prophylaxis as compared to those who did not $(35 \%$ vs. $8 \%, p<0.001)$ [14].

Tricarichi et al. found a $58 \%$ rate of carbapenem resistant (CR) among 278 K. pneumoniae BSI (KP-BSI) in patients with hematologic malignancies; the higher incidence of $K$. pneumoniae carbapenem resistant (KP-CR) was identified in acute myeloid leukemia (AML) patients (74\%) but acute lymphoblastic leukemia (ALL) and non-Hodgkin lymphoma (NHL) did not have a negligible rate of KP-CR (7\% and $11 \%$ respectively). The presence of KP-CR translated into a high mortality rate compared to carbapenem-susceptible KP (52\% vs. $14 \%$ ) [15].

A more recent study investigated the changing epidemiology of BSI in HSCT recipients over a 25 years period: 1164 BSI have been included in the analysis occurring at a median time of 55 days post-HSCT. The rate of Gram-positive BSI decreased from 68\% in 1993-2012 to 52\% in 2013-2017 while there was the concomitant increase of Gram-negative BSI from $32 \%$ to $42 \%$ as well as of MDR Gram-negative bacteria from $1 \%$ up to $10 \%$ [16]. Table 1 shows the major risk factors for developing Multi-Drug Resistant bacterial infections. 
Table 1. Risk factors for Multi-Drug resistant bacterial infections

\begin{tabular}{|c|c|c|c|c|}
\hline MRSA & VRE & CRE & MDR PA & AB \\
\hline $\begin{array}{l}\text { Age (HA-MRSA > } 65 \text { ys, } \\
\text { CA-MRSA younger) }\end{array}$ & Advanced age (>65 ys) & Advanced age (>65 ys) & Advanced age (>65 ys) & Advanced age (>65 ys) \\
\hline $\begin{array}{l}\text { Prolonged or prior hospitalization } \\
\text { (>HA-MRSA) }\end{array}$ & Transplant recipient & Transplant recipient & Neutropenia/immunosuppression & Critically ill patients admitted to ICU \\
\hline ICU admission & HD & $\begin{array}{l}\text { Prior and prolonged ATB use last } 90 \text { days } \\
\text { (notably glycopeptides, FQ, CIII-IV, } \\
\text { anti-anaerobes, carbapenems) }\end{array}$ & Use of broad spectrum antibiotics & $\begin{array}{l}\text { Prior and prolonged atb use last } 90 \text { days } \\
\text { (notably AG, FQ, CIII and carbapenems) }\end{array}$ \\
\hline HD & $\begin{array}{l}\text { Prolonged or prior } \\
\text { hospitalization }\end{array}$ & Presence of invasive devices & Malnutrition & Burns and surgical wounds \\
\hline Indwelling line, catheters & ICU admission & ICU admission (with or without MV) & Structural lung disease & $\begin{array}{l}\text { High CCI (notably diabetes, chronic lung, } \\
\text { liver and renal diseases) }\end{array}$ \\
\hline $\begin{array}{l}\text { Invasive procedures or recent } \\
\text { surgery }\end{array}$ & Surgery & Decubitus ulcer & Malignancy & Prolonged or prior hospitalization \\
\hline Institutionalization & High CCI & Prolonged or prior hospitalization & Prolonged or prior hospitalization & Malignancy \\
\hline High CCI & Invasive devices & Poor functional state & $\begin{array}{l}\text { Prior and prolonged ATB use last } 90 \text { days } \\
\text { (notably AG, FQ, CIII and carbapenems) }\end{array}$ & Transplant recipient \\
\hline PWID & $\begin{array}{l}\text { Prior and prolonged atb use last } \\
90 \text { days (notably vancomycin, } \\
\text { FQ, CIII, anti-anaerobes, } \\
\text { carbapenems) }\end{array}$ & Indwelling devices & Presence of invasive devices & Presence of invasive devices \\
\hline Athletes (>CA-MRSA) & Malignancy & Surgical interventions & Transplant recipient & HD \\
\hline $\begin{array}{l}\text { Prior and prolonged ATB use last } \\
90 \text { days (>HA-MRSA) }\end{array}$ & Neutropenia/immunosuppression & Transfer between units & $\begin{array}{l}\text { High CCI (notably diabetes, chronic lung, } \\
\text { liver and renal diseases) }\end{array}$ & Severe underlying illness \\
\hline $\begin{array}{l}\text { Crowded Living Enviroment } \\
\quad(>\text { CA-MRSA) }\end{array}$ & Institutionalization & $\begin{array}{l}\text { High CCI (notably diabetes, chronic lung, } \\
\text { liver and renale diseases) }\end{array}$ & ICU admission & Neutropenia/immunosuppression \\
\hline
\end{tabular}




\subsection{MDR Colonization and BSI}

Several studies evaluated the relationship between MDR colonization and the risk of developing BSI. Girmenia et al. found that a KP-CR colonization before or after the transplant was followed by a BSI in $25 \%$ of the cases of autologous and $39 \%$ of the cases of allogeneic HSCT [17]; infection-related mortality was $16 \%$ among autologous and $70 \%$ among allogeneic HSCT recipients. A subsequent Italian prospective study analyzed the epidemiology of pre-engraftment Gram-negative BSIs in patients receiving allogeneic $(n=1118)$ and autologous $(n=1625)$ HSCT. Overall, the cumulative incidence of pre-engraftment Gram-negative BSI was 17\% in allogeneic and 9\% in autologous HSCT recipients. In allogeneic HSCT patients, E. coli accounted for 52\% of Gram-negative BSI, KP for 19\% and P. aeruginosa (PA) for $14 \%$ of BSI. The presence of pre-HSCT colonization from KP-CR was associated with a $28 \%$ probability of developing a post-HSCT BSI from the same isolate, while the risk of KP-CR BSI for patients who were not colonized before the graft was only $0.4 \%$. Similar results were shown for MDR PA ( $28 \%$ vs. $0.6 \%)$, ESBL E. coli (9\% vs. $1.3 \%$ ) and ESBL K. pneumoniae (7\% vs. $0.4 \%$ ) [18].

Staphylococci are the most frequent Gram-positive pathogen isolated in BSI and coagulase-negative Staphylococci (CoNS) are responsible for approximately a quarter of BSI, while S. aureus is found in around $5 \%$ of cases [2]. S. aureus is more virulent than CoNS; in particular, if methicillin resistance occurs, mortality is higher. Risk factors for MRSA are, among the others, previous nasal colonization and the presence of a central venous line.

Enterococci are commensals of the gastrointestinal (GI) tract and can affect $10-12 \%$ of transplant recipients [3]. E. faecalis used to be the main strain encountered even if in some centers E. faecium is replacing it. For both strains, E. faecalis and E. faecium vancomycin resistance has increased, causing a higher mortality rate [6]. Viridans streptococci are found in approximately $5 \%$ of BSI with a mortality and morbidity not negligible [4] with consequent high mortality. The frequently use of vancomycin in the empiric therapy is possibly associated with a higher rate of pharmacological pressure and secondary risk of resistant pathogen selection.

\section{Antibiotic Prophylaxis}

Several meta-analyses addressing the issues of anti-microbial prophylaxis in neutropenic patients have been published. The Cochrane evaluated 109 trials between 1973 and 2010, including 70 studies in patients with hematologic malignancies [19]. Different antibiotic prophylactic regimens have been administered, namely FQ, trimethoprim-sulfamethoxazole (TMP-SMZ), non-absorbable antibiotics, rifampicin, and even IV prophylaxis. All-cause mortality resulted in being significantly reduced with FQ prophylaxis compared to placebo or no treatment as well as infection-related mortality, the number of febrile episodes and Gram-negative/Gram-positive BSI. On the other hand, compared to placebo, patients receiving prophylaxis were more likely to harbor resistant bacteria to the specific drug.

Kern et al. prospectively analyzed the impact of FQ prophylaxis on BSI in a large number of patients who received different treatments, for instance high-dose chemotherapy for acute leukemia, autologous or allogeneic HSCT. Overall, the use of prophylaxis was associated with less Gram-negative BSI but a greater incidence of Gram-positive BSI. In addition, patients receiving FQ prophylaxis had significantly more BSI due to ESBL-positive Enterobacteriaceae. All-cause mortality was positively affected by prophylaxis only in patients receiving high-dose chemotherapy for acute leukemia [20].

A recent meta-analysis investigated the efficacy of levofloxacin in patients with acute leukemia. Prophylaxis reduced the incidence of febrile neutropenia and microbiologically documented infections but did not have effect on mortality [21].

Kimura et al. reported the results of a meta-analysis evaluating 17 trials including 1453 patients who received autologous $(n=842)$ or allogeneic HSCT $(n=407)$ [22]. Similarly, to the previous studies, systemic antibiotic prophylaxis reduced the number of febrile episodes, clinically or microbiologically documented infections and BSI, while all-cause mortality and infection-related mortality did not result affected by the antibiotic prophylaxis. 
An Italian study analyzed 342 cases of $E$. coli BSIs occurring in onco-hematologic patients between 2016 and 2017. In multivariate analysis, FQ prophylaxis emerged as a risk factor for the emergence of ESBL E. coli [7].

\section{Guidelines}

The ECIL guideline published in 2007 recommended FQ prophylaxis based on two randomized trials and one meta-analysis. Subsequently, indications for antibiotic prophylaxis were rather discordant with some groups still maintaining the indication and others discouraging the use of prophylaxis. Nevertheless, over the most recent years the emergence of MDR bacteria strongly correlated with the wide use of prophylaxis, raised concerns for usefulness of this strategy. According to these observations, the American Society of Clinical Oncology (ASCO) and the Infectious Diseases Society of America (IDSA) guidelines published in 2018 recommend FQ prophylaxis in high-risk patients, namely those with acute leukemia and HSCT recipients [23].

The German guidelines reinforce the concept that FQ prophylaxis demonstrated its efficacy in reducing the incidence of Gram-negative sepsis during neutropenia without significant changes in mortality [24]; in particular at institutions with a low rate of MDR Gram-negative bacteria, antibacterial prophylaxis remains a reasonable choice to reduce the incidence of Gram-negative sepsis during neutropenia (AII). In patients with chronic graft versus host disease (cGVHD) on immunosuppressive therapy, antibiotic prophylaxis against encapsulated bacteria might be useful until immunizations can be applied (BIII). A summary of recommendations is given in Figure 1 according to the main international guidelines in hematological patients.

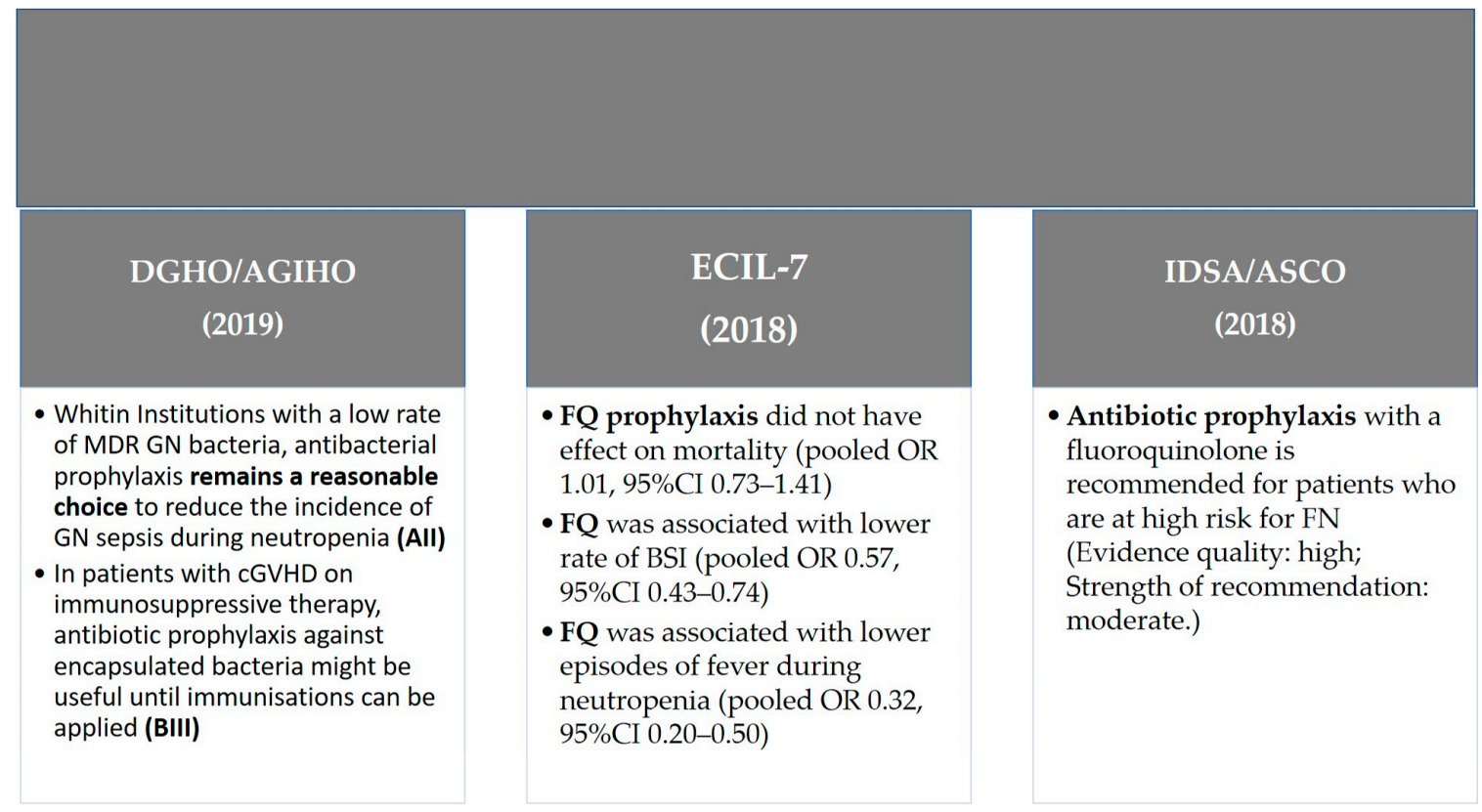

Figure 1. Guidelines recommendations of antibiotic prophylaxis in hematologic patients. Abbreviations: GN-Gram-negative; FQ-fluoroquinolone.

\section{Sepsis/Septic Shock}

Sepsis and septic shock represent a major challenge for physicians treating neutropenic hematological patients. The high rate of morbidity and mortality and the need for prompt intensive care, related to the peculiar clinical characteristics and the immunocompromised status of the patients, are of particular concern and require a multi-disciplinary approach. The prevalence of sepsis in neutropenic hematological patients is not precisely defined, and most studies do not analyze specific subgroups as immunocompromised patients. 


\subsection{Definition}

Since 1991, sepsis has been described as a host's systemic inflammatory response syndrome (SIRS) to infection, defined by two or more of the following criteria: temperature $>38^{\circ}$ or $<36^{\circ}$, heart rate $>90 / \mathrm{min}$, respiratory rate $>20 / \mathrm{min}$, white blood cell count $>12,000 / \mathrm{mm}^{3}$ or $<4000 / \mathrm{mm}^{3}$ or $>10 \%$ immature bands. The 2016 Surviving Sepsis Campaign (SSC), overcoming the previous SIRS criteria that can reflect an adaptive and appropriate response to infection, defined sepsis as a life-threatening organ dysfunction caused by a dysregulated host response to infection and septic shock as a subset of sepsis with circulatory and cellular/metabolic dysfunction associated with a higher risk of mortality. Both the diagnosis and treatment of sepsis and septic shock in hematological patients should not differ from those used in the general population [25-27].

The SSC and especially the 2018 Update Bundle remark that sepsis is a medical emergency and resuscitation, and management must start immediately (hour-1 Bundle) [28].

A bundle is a series of interventions that together or at a multi-disciplinary level, result in a reduction of an event or an improvement in the quality of care or in the prevention efforts.

\subsection{Diagnosis}

In the setting of a febrile neutropenic hematological patient, the diagnosis of sepsis may be challenging, and fever can be the only manifestation of an underlying critical condition.

Sepsis is a clinical diagnosis, but different scores have been developed, mainly in the settings of emergency medicine or the intensive care unit (ICU), to identify patients likely to have sepsis. The most used scores are the sequential organ failure assessment (SOFA) score that comprehends a set of laboratory data (as platelet count, creatinine and hepatic function) and the quick SOFA, a clinical score that provides simple bedside criteria (respiratory rate $\geq 22 / \mathrm{min}, \mathrm{GCS}<15$ and a systolic blood pressure $\leq 100 \mathrm{mmHg}$ ). Compared to SIRS criteria, these scores can be altered by a massive dysregulated response of the organism to infection and represent the mainstay of a rapid diagnosis. Sepsis is defined as an infection with a qSOFA and a SOFA score $\geq 2$. Septic shock is considered a subset of sepsis with persistent hypotension requiring a vasopressor to maintain a mean arterial pressure (MAP) $\geq 65 \mathrm{mmHg}$ despite adequate fluid resuscitation and an increase in serum lactate $\geq 2 \mathrm{mmol} / \mathrm{L}$ [29].

The value of these scores in the neutropenic hematological population is less established. A recent study considering both hematological and solid cancer patients shows that the SSC's new definition of sepsis and septic shock is applicable in an ICU setting with the same reliability as in the general population. In the ICU, the SOFA score seems more accurate than qSOFA and SIRS criteria to predict hospital mortality; however, outside of the ICU, qSOFA is useful and easily calculated [30].

\section{Treatment}

The following issues should be taken into account when we consider the initial antibiotic treatment of a neutropenic hematological patient with fever:

- High-risk patients (those with an expected severe neutropenia duration $\geq 7$ days, for example HSCT recipients or this candidate for intensive chemotherapy);

- Hemodynamic stability and illness severity;

- Previous colonization by MDR bacteria, detected on routine swabs (ESBL or carbapenemasesproducing Enterobacteriales (CPE), MRSA, VRE);

- Previous infections by MDR bacteria;

- Local epidemiological resistance patterns [31].

The initial treatment of neutropenic fever should consider all these variables. Important risk factors for developing MDR infections are exposure to broad-spectrum antibiotic therapy, especially within the last month before the infectious episode, in-hospital/ICU staying, prior colonization, indwelling devices [32,33], all frequently found in HSCT recipients and hematological patients. BSI from MDR 
Gram-negative bacteria is associated with significantly lower overall survival (OS) compared to hematological patients with non-MDR Gram-negative BSI [15,34,35].

There are two possible approaches when starting an empiric antibiotic treatment in patients with neutropenic fever: escalation or de-escalation.

- The 2010 IDSA guidelines recommend that if no risk factors for complicated fever or MDR infection are present or suspected and the patient is stable, an escalation strategy should be performed, starting from a monotherapy with an anti-pseudomonal B-lactam agent, such as cephalosporin (e.g., cefepime), carbapenems (meropenem or imipenem-cilastatin) or piperacillin-tazobactam, covering the most common bacteria (AI) [36]. The guidelines report rising resistance rates among Gram-negative bacteria with the use of ceftazidime monotherapy, with the limited activity of this agent against Gram-positive bacteria. The latest ECIL guidelines are in line with this escalation approach in non-colonized, uncomplicated patients. Monotherapy with piperacillin/tazobactam or cefepime and ceftazidime (the latter not to be used as empirical monotherapy in a setting of high ESBL prevalence) is a valid option (AI). Altogether, in patients without critical presentation and no risk factors for resistance to other agents, ECIL recommends a carbapenem-sparing approach [32].

- Antibacterial spectrum should be broadened in cases of clinical worsening, documented infection, or isolation of resistant microorganisms. An anti-Gram-positive agent should be added if such an infection is suspected: evidence of central venous catether (CVC) dysfunction or infection, pneumonia, hemodynamic instability, soft tissue, or skin infection.

- In case of known colonization with MDR bacteria, mostly consistent with the use of whatever strategy of colonization study, a previous infection with resistant bacteria or a critical clinical presentation, a de-escalation approach is preferred, aiming at covering a wide spectrum of bacteria while awaiting the final etiological diagnosis and the possibility of de-escalate, then reducing the number of antibiotics or the spectrum of antibacterial treatment. Anti-microbial de-escalation is thought to decrease exposure to broad-spectrum antimicrobials and to prevent the emergence of anti-microbial resistance. Valid options of treatment are carbapenem monotherapy, for example in case of suspected ESBL Gram-negative infection, or combinations, as $\beta$ Lactam/ $/$ lactamase inhibitor (BLBLI) plus aminoglycoside. A randomized trial on 379 patients with ESBL Gram-negative BSI (13\% neutropenic) showed a survival advantage of meropenem with piperacillin/tazobactam monotherapy, although patients were exposed to very heterogeneous empirical antibiotic regimens before randomization [37]. In confirmed MDR BSI a combination treatment is required and old antibiotics (like fosfomycin and colistin) should not be given as monotherapy but with other drugs regarding the potential risk of generating resistant strains. Figure 2 summarizes bacterial susceptibility to the most relevant antibiotics.

Early reassessment at $48-72 \mathrm{~h}$ and narrowing of the antibiotic spectrum until discontinuation are advised when the patient is hemodynamically stabilized or a targeted pathogen is isolated. Early de-escalation and discontinuation also applies for HSCT recipients. A study from Snyder et al. on 120 HSCT recipients showed that de-escalation after five days of broad-spectrum therapy and defervescence did not increase the rate of recurrent fever and the clinical outcome, compared to those who continued antibiotic treatment until neutropenia recovery [38]. These considerations are confirmed by a study of Gustinetti et al. on 110 HSCT patients in the pre-engraftment phase, where de-escalation therapy was feasible in $60 \%$ of patients. Failures of early or late de-escalation occurred in 10 patients $(17.5 \%)$; however, no cases of septic shock or death have been reported [39]. This approach is safe even in critically ill neutropenic patients in the ICU setting [40]. 


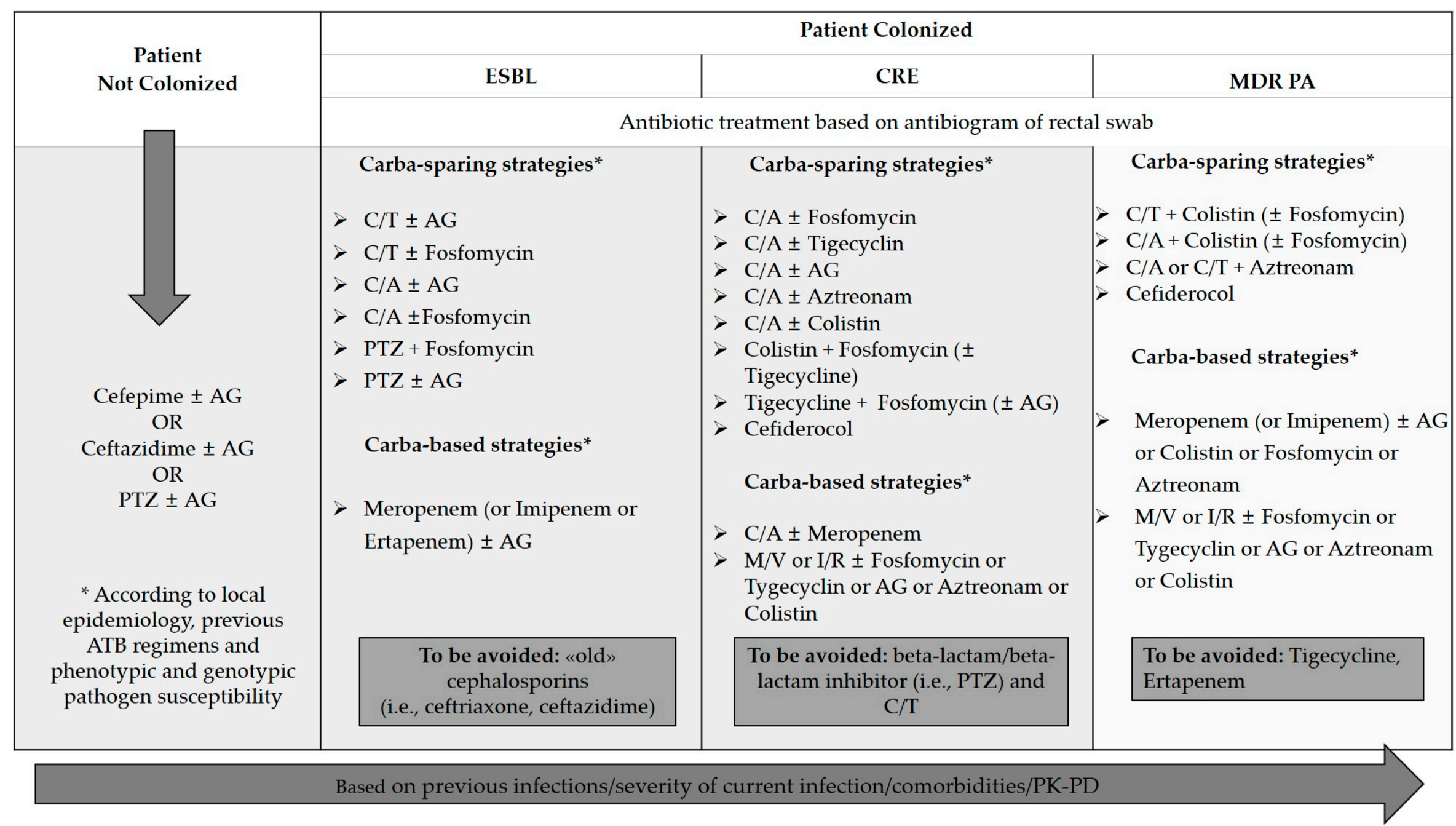

Figure 2. First-line antibiotic treatment in hematologic patients with neutropenic fever. Abbreviations: ESBL: extended-spectrum beta-lactamase; CRE: carbapenem-resistant Enterobacteriaceae; MDR PA: multi-drug-resistant Pseudomonas aeruginosa. C/A: ceftazidime/avibactam; C/T: ceftolozane/tazobactam; AG: aminoglycosides; PTZ: piperacillin-tazobactam; M/V: meropenem/vaborbactam. 
A study from Gutierrez-Gutierrez on 480 patients with CPE-BSI showed that initial appropriate anti-microbial therapy was associated with 30-day lower mortality compared to patients who received inappropriate therapy (38.5\% vs. $60.6 \%$ ). Among those receiving appropriate therapy, $39 \%$ received combination therapy, and $61 \%$ received monotherapy. Overall mortality was not different between those receiving combination therapy or monotherapy ( $35 \%$ vs. $41 \%$ ). However, combination therapy was associated with lower mortality than was monotherapy in the high-mortality-score stratum (patients with sepsis/septic shock, PITT score $>6$, Charlson score $>2$ ), but not in the low-mortality score stratum [41].

Even in neutropenic septic patients, the first option is represented by an anti-pseudomonal broad-spectrum agent (e.g., piperacillin/tazobactam or meropenem). The use of a combination therapy with aminoglycosides in neutropenic patients with sepsis is a matter of debate, with some studies showing any significant advantage and increasing renal toxicity [42]. By contrast, Krumar et al. showed that early combination antibiotic therapy (B-lactam plus aminoglycoside, FQ or macrolides/clindamycin) improved survival in critically ill neutropenic patients compared to monotherapy [43]. One recent study showed that in neutropenic hematological patients with sepsis or septic shock, aminoglycoside combination therapy was not associated with increased renal toxicity and led to a reduction in the mortality rate [44]. According to these observations, the main international guidelines recommend the use of combination therapy including aminoglycosides in critically ill patients $[25,32,36]$.

A de-escalation policy may be considered wise, as soon as a specific pathogen is identified or in case the absence of any isolate and clinical improvement is documented [25,45-47].

In patients with septic shock, recommendations include initial fluid resuscitation with $30 \mathrm{~mL} / \mathrm{kg}$ of crystalloid within the first $3 \mathrm{~h}$ started within the first hour from the beginning of sepsis symptoms, to obtain a MAP $\geq 65 \mathrm{mmHg}$, which is the threshold below at which tissue perfusion becomes linearly dependent on arterial pressure. A continuous re-evaluation of the patient is warranted to assess the responsiveness of fluid therapy. If fluid resuscitation is not enough to maintain a permissive MAP in a shocked patient, a vasoactive medication is needed, with norepinephrine as the agent of first choice.

Steroid therapy should not be systematically used in patients responsive to effective fluid or vasopressor therapy. However, a conservative strategy regarding red blood cells transfusion should be used, with a transfusion threshold $<7 \mathrm{~g} / \mathrm{dL}$ if no risk factors are present.

Neutropenic septic patients should not be treated differently from the non-neutropenic population concerning all other intensive care procedures (e.g., sedation, analgesia, glucose control, bicarbonate therapy and nutrition) $[25,26]$.

\subsection{Carbapenemases, Carbapenem-Resistant Enterobacteriacae, and Novel Antibiotics}

Several mechanisms of antibiotic resistance have been described for Gram-negative bacteria, which are not uncommon in the hematological setting. Beta-lactamases can be subdivided according to Ambler's classification into four main classes, each with its own peculiarities:

1. Class A $\beta$-lactamases include penicillinases and cephalosporinases, such as TEM, SHV, CTX-M, PER, VEB, GES, and IBC, with development of resistance to carboxypenicillins, ureidopenicillins, and aztreonam [48,49]. This class also comprises Klebsiella pneumoniae carbapenemases (KPC) enzymes and GES-2, which can hydrolyze carbapenems [49,50].

2. Class $B$ are defined as metallo- $\beta$-lactamases (MBL), including IMP, verone integron-encoded metallo-beta-lactamase (VIM), New Delhi metallo-beta-lactamases (NDM), SPM, and GIM, which initially emerged in Asian countries and later disseminated among Enterobacteriaceae worldwide [50-52].

3. Class $\mathrm{C}$ comprises intrinsic and inducible resistance mechanisms, such as AmpC-type cephalosporinase, not inhibited by clavulanic acid, tazobactam, and sulbactam. The structural modifications of AmpC may confer reduced susceptibility to new b-lactam-b-lactamase inhibitors (BLBLIs), ceftolozane/tazobactam, and ceftazidime/avibactam [50-53]. 
4. Class D oxacillinases provide resistance to all penicillins, 3- and 4-generation cephalosporines (3GCs) and aztreonam. OXA enzymes such as OXA-198 are known mechanisms of carbapenem resistance [50,54]; other OXA b-lactamases (mainly OXA-48) express low activity against carbapenems, hydrolyzing imipenem better than meropenem $[50,54]$.

In addition to the introduction of novel but now well-known cephalosporins such as ceftolozane/tazobactam and ceftazidime/avibactam, therapeutic options for CRE infections have been added to the equipment. The combination of meropenem and a boronic acid beta-lactamase, vaborbactam $(\mathrm{M} / \mathrm{V})$, has shown increased in vitro activity against Class $A$ and Class $C$ serine b-lactamases; however, Class B (e.g., NDM, VIM) and Class D (e.g., OXA-48) carbapenemases are not inhibited by vaborbactam [55]. The efficacy, tolerability, and safety of $\mathrm{M} / \mathrm{V}$ was first assessed in TANGO I [55], a multi-center, double-blind, randomized, Phase III, noninferiority trial versus P/T for the treatment of cUTIs and TANGO II [56], in which M/V was compared to the best available treatment (BAT) in a series of infections because of suspected or known CRE (notably cUTI, hospital-acquired or ventilator-associated bacterial pneumonia [HABP/VABP], complicated intrabdominal infections [cIAI], and bacteremia). Because of the superiority of $\mathrm{M} / \mathrm{V}$ compared to the BAT, this study was terminated prematurely. A Phase III trial called TANGO III, in which M/V was compared to PTZ for the treatment of HABP/VABP, was withdrawn by sponsor decision [57]. Imipenem/cilastatin with relebactam (I/R) combines an approved carbapenem with a novel b-lactamase inhibitor [58]. The in vitro addition of relebactam showed increased activity of imipenem against ESBLs, serine b-lactamases, and P. aeruginosa; however, relebactam cannot inhibit Class D OXA-48 [58]. A Phase II study assessed the efficacy, tolerability, and safety of I/R versus imipenem/cilastatin in cIAI and cUTI [58]. In addition, two Phase III studies, RESTORE-IMI 1 [59] and RESTORE-IMI 2 [60], are currently evaluating I/R in different settings. RESTORE-IMI 1 is a multi-center, randomized, double-blind, comparator-controlled trial that compares the efficacy and safety of I/R versus colistin and imipenem/cilastatin (COL p IMI) in patients with imipenem-nonsusceptible bacterial infections, including HABP, VABP, cIAI, and cUTIs [59]. In the RESTORE-IMI 2 trial, I/R was compared to PTZ (both arms with the addition of linezolid) in $\mathrm{HABP} / \mathrm{VABP}[60]$.

Cefiderocol is a novel siderophore cephalosporin designed to target $\mathrm{CR}$ pathogens, including CR strains of Enterobacteriaceae (CRE), Pseudomonas aeruginosa, Acinetobacter baumannii, and Stenotrophomonas maltophilia, which is intrinsically CR [61,62]. CREDIBLE CR is a randomized, open-label, prospective, Phase III clinical study and was designed to evaluate cefiderocol in patients with CR Gram-negative infections regardless of species or infection site source, even including sepsis and BSIs [61,62]. Hsueh et al. evaluated the in vitro microbiological profiles of cefiderocol, ceftolozane/tazobactam, and ceftazidime/avibactam against P.aeruginosa, S. and A. baumannii, and S. maltophilia isolates within the bloodstream. Cefiderocol exhibited significantly more potent in vitro activity when compared to comparators with MICs $\leq 4 \mathrm{mg} / \mathrm{L}$ for the five colistin- and imipenem-resistant $P$. aeruginosa isolates and $70 \%$ of the ten colistin- and imipenem-resistant isolates [63]. Currently, high-dose and combination strategies that could have the new $\beta$-lactam/ $\beta$-lactamase inhibitors should be considered in severe CRE infections to maximize treatment success [64]. Cefiderocol is added to these therapeutic options, widening on the A. baumannii and S. maltophilia sides, which have often been excluded from the spectrum of new molecules over the last decade [64,65].

Figure 2 summarizes the first-line antibiotic treatment that might be suggested in hematologic patients with neutropenic fever.

In addition to the use of antibiotics, source control represents an aspect of remarkable importance for the successful treatment strategy of neutropenic patients with fever. Roughly all patient candidates in an intensive chemotherapy treatment have a central line catheter (CVC): when patients become febrile, clinicians should carefully evaluate CVC as a possible source of infection. According to these observations Table 2 shows main indications for CVC removal in hematology patients. 
Table 2. Summary of the indications for catheter removal in hematologic patients.

Bloodstream infections due to

- $\quad S$ aureus, VRE, P aeruginosa, stenotrophomonas maltophilia, Acinetobacter, MDR bacteria

- Candida

- Mycobacteria

- Less virulent pathogens if $\geq 2$ blood cultures revealing the same pathogen

Persistent infection despite $\geq 72 \mathrm{~h}$ of effective therapy

Clinical instability despite anti-microbial therapy

Sepsis and septic shock

Severe complications (Endocarditis, septic thrombosis, abscess)

Tunnel infection or port pocket site infection

\subsection{Treatment Duration}

Antibiotic duration in neutropenic patients with fever of unknown origin (FUO) is a matter of debate. While the Infectious Diseases Society of America (IDSA) and the European Society for Medical Oncology (ESMO) guidelines recommend continuing antibiotic treatment until neutropenia recovery $\left(\mathrm{ANC} \geq 500 \mathrm{cells} / \mathrm{mm}^{3}\right.$ ), ECIL guidelines recommend discontinued antibiotics if patients are stable for at least $72 \mathrm{~h}$ and remain afebrile for $48 \mathrm{~h}$ despite the neutrophil count $<0.5 \times 10^{9} / \mathrm{L}$. This approach has been demonstrated to be safe in several studies [66,67]. AGIHO/DGHO guidelines recommend a semi-conservative approach, discontinuing empiric antibiotic treatment in severe neutropenic patients afebrile for $\geq 7$ days without signs of infection [68].

In cases of documented infection or critically ill neutropenic patients, antibiotic treatment should continue until the infection is microbiologically eradicated or until all clinical signs are resolved for at least 7 to 10 days, depending on the patient's condition and the infection site.

However, a recent survey from the EBMT work group analyzing current anti-microbial practices in febrile neutropenia across the world showed that ECIL guidelines are not widely implemented in clinical practice [69]. The major deviations from guidelines resulted in the overuse of combination therapy $(1 / 3$ of centers) or the use of carbapenems ( $10 \%$ of centers) as first-line therapy in non-complicated/colonized hematological patients, without further de-escalation and no early discontinuation in case of uncomplicated FUO (1/3 of centers) [69]. Perhaps clinicians feel uncomfortable when dealing with resistant pathogens, especially in centers with a high rate of resistance.

\subsection{Management of Critically Ill Neutropenic Patients}

Since the survival of hematological patients has increased over time, due to new effective therapies and better supportive care, the number of patients admitted to the ICU has increased proportionally. Compared to the past, mortality in critically ill cancer patients with sepsis or septic shock admitted to the ICU has significantly decreased [70]. Several studies confirm that the delayed alert of an ICU team correlates with lower survival, making it more difficult to manage critical situations [71-74].

ICU admission policies are lacking, partly because of a lack of universal scores able to identify deteriorating patients likely to benefit from ICU treatment [75]. Typically, a full code with no restrictions in intensive treatment should be applied to patients in complete remission of the malignancy, in patients receiving first-line therapy and in patients with curative therapeutic options, considering performance status, prognosis and the concept that critical care survival is largely determined by the acute critical illness rather than the underlying hematological malignancy. A full code status with a time-limited trial and frequent reassessment should be applied in patients with a potentially reversible cause of deterioration or uncertain prognosis [76,77]. Neutropenia should no longer be considered a negative prognostic factor in managing these patients, even in allo-HSCT recipients [78-80]. A meta-analysis of more than 2000 HSCT patients in the ICU showed the main prognostic factors of mortality were multi-organ failures requiring support and uncontrolled graft versus host disease (GVHD), not septic 
shock, underlying malignancy or disease status, suggesting that they should not be used in the ICU transfer decision process [81]. Therefore, strict collaboration between intensivists and hematologists should be advised.

\section{Conclusions and Key Points}

The management of hematologic patients who exhibit neutropenic fever represents a challenging issue in the daily clinical practice. The best approach has not yet been defined, but certainly should include a multi-disciplinary strategy. In this respect, the co-operation with ICU, infectious disease specialists, and microbiology seems of paramount importance.

It is extremely important to know the epidemiology of own Center: this allows to set up antibiotic treatment strategies tailored to the pathogens most frequently identified.

Infections due to MDR bacteria represent a life-threatening complication for hematologic patients. To tackle this problem is important to preserve the activity of the old compounds as well as to limit the uncontrolled use of the new antibiotics.

Table 3 describes the most relevant strategies to optimize the antibiotic treatment in hematologic patients with BSI.

Table 3. Strategies to optimize the anti-microbial treatment in hematologic patients with BSI.

\begin{tabular}{cc}
\hline Main Objective & Intervention \\
\hline Identify colonized patients with MDR bacteria & $\begin{array}{c}\text { Monitor patients with rectal swab for ESBL, KPC, and PA } \\
\text { MDR bacteria }\end{array}$ \\
\hline $\begin{array}{c}\text { Initial anti-microbial treatment: } \\
\text { escalation vs. de-escaltion strategy }\end{array}$ & $\begin{array}{c}\text { Knowledge of the local epidemiology } \\
\text { Source control }\end{array}$ \\
$\begin{array}{c}\text { Consider CVC removal } \\
\text { timely radiologic evaluation (CT scan, MRI etc.) }\end{array}$ \\
\hline Antibiotic stewardship programs & $\begin{array}{c}\text { Education, audit, guidelines implementation, antibiotic } \\
\text { cycling/restriction }\end{array}$ \\
\hline
\end{tabular}

Abbreviations: ESBL: extended-spectrum beta-lactamase; KPC: Klebsiella pneumoniae carbapenemase producing; MDR PA: multi-drug-resistant Pseudomonas aeruginosa; CT: computed tomography; MRI: magnetic resonance imaging.

Funding: This research received no external funding.

Conflicts of Interest: The authors declare no conflict of interest.

\section{References}

1. Mikulska, M.; Del Bono, V.; Raiola, A.M.; Bruno, B.; Gualandi, F.; Occhini, D.; di Grazia, C.; Frassoni, F.; Bacigalupo, A.; Viscoli, C. Blood stream infections in allogeneic hematopoietic stem cell transplant recipients: Reemergence of Gram-negative rods and increasing antibiotic resistance. Biol. Blood Marrow Transplant. 2009, 15, 47-53. [CrossRef]

2. Oliveira, A.L.; de Souza, M.; Carvalho-Dias, V.M.; Ruiz, M.A.; Silla, L.; Tanaka, P.Y.; Simões, B.P.; Trabasso, P.; Seber, A.; Lotfi, C.J.; et al. Epidemiology of bacteremia and factors associated with multi-drug-resistant gram-negative bacteremia in hematopoietic stem cell transplant recipients. Bone Marrow Transplant. 2007, 39, 775-781. [CrossRef]

3. Poutsiaka, D.D.; Munson, D.; Price, L.L.; Chan, G.W.; Snydman, D.R. Blood stream infection (BSI) and acute GVHD after hematopoietic SCT (HSCT) are associated. Bone Marrow Transplant. 2011, 46, 300-307. [CrossRef]

4. Blennow, O.; Ljungman, P.; Sparrelid, E.; Mattsson, J.; Remberger, M. Incidence, risk factors, and outcome of bloodstream infections during the pre-engraftment phase in 521 allogeneic hematopoietic stem cell transplantations. Transpl. Infect. Dis. 2014, 16, 106-114. [CrossRef]

5. Young, J.H.; Logan, B.R.; Wu, J.; Wingard, J.R.; Weisdorf, D.J.; Mudrick, C.; Knust, K.; Horowitz, M.M.; Confer, D.L.; Dubberke, E.R.; et al. Infections after Transplantation of Bone Marrow or Peripheral Blood Stem Cells from Unrelated Donors. Biol. Blood Marrow Transplant. 2016, 22, 359-370. [CrossRef] [PubMed] 
6. EORTC. International Antimicrobial Therapy Cooperative Group Gram-positive bacteraemia in granulocytopenic cancer patients. Eur. J. Cancer 1990, 26, 569-574. [CrossRef]

7. Mikulska, M.; Viscoli, C.; Orasch, C.; Livermore, D.M.; Averbuch, D.; Cordonnier, C.; Akova, M. Aetiology and resistance in bacteraemias among adult and paediatric haematology and cancer patients. J. Infect. 2014, 68, 321-331. [CrossRef] [PubMed]

8. Tatarelli, P.; Mikulska, M. Multidrug-resistant bacteria in hematology patients: Emerging threats. Future Microbiol. 2016, 11, 767-780. [CrossRef]

9. Tumbarello, M.; Spanu, T.; Caira, M.; Trecarichi, E.M.; Laurenti, L.; Montuori, E.; Fianchi, L.; Leone, F.; Fadda, G.; Cauda, R.; et al. Factors associated with mortality in bacteremic patients with hematologic malignancies. Diagn. Microbiol. Infect. Dis. 2009, 64, 320-326. [CrossRef]

10. Magiorakos, A.-P.; Srinivasan, A.; Carey, R.; Carmeli, Y.; Falagas, M.; Giske, C.; Harbarth, S.J.; Hindler, J.; Kahlmeter, G.; Olsson-Liljequist, B.; et al. Multidrug-resistant, extensively drug-resistant and pandrug-resistant bacteria: An international expert proposal for interim standard definitions for acquired resistance. Clin. Microbiol. Infect. 2012, 18, 268-281. [CrossRef] [PubMed]

11. Cassini, A.; Högberg, L.D.; Plachouras, D.; Quattrocchi, A.; Hoxha, A.; Simonsen, G.S.; Colomb-Cotinat, M.; Kretzschmar, M.E.; Devleesschauwer, B.; Cecchini, M.; et al. Attributable deaths and disability-adjusted life-years caused by infections with antibiotic-resistant bacteria in the EU and the European Economic Area in 2015: A population-level modelling analysis. Lancet Infect. Dis. 2019, 19, 56-66. [CrossRef]

12. Viscoli, C.; Varnier, O.; Machetti, M. Infections in patients with febrile neutropenia: Epidemiology, microbiology, and risk stratification. Clin. Infect. Dis. 2005, 40, S240-S245. [CrossRef] [PubMed]

13. Klastersky, J.; Ameye, L.; Maertens, J.; Georgala, A.; Muanza, F.; Aoun, M.; Ferrant, A.; Rapoport, B.; Rolston, K.; Paesmans, M. Bacteraemia in febrile neutropenic cancer patients. Int. J. Antimicrob. Agents 2007, 30, S51-S59. [CrossRef] [PubMed]

14. Averbuch, D.; Tridello, G.; Hoek, J.; Mikulska, M.; Akan, H.; Segundo, L.Y.S.; Pabst, T.; Özçelik, T.; Klyasova, G.; Donnini, I.; et al. Antimicrobial Resistance in Gram-Negative Rods Causing Bacteremia in Hematopoietic Stem Cell Transplant Recipients: Intercontinental Prospective Study of the Infectious Diseases Working Party of the European Bone Marrow Transplantation Group. Clin. Infect. Dis. 2017, 65, 1819-1828. [CrossRef] [PubMed]

15. Trecarichi, E.M.; Pagano, L.; Martino, B.; Candoni, A.; Di Blasi, R.; Nadali, G.; Fianchi, L.; Delia, M.; Sica, S.; Perriello, V.; et al. Bloodstream infections caused by Klebsiella pneumoniae in onco-hematological patients: Clinical impact of carbapenem resistance in a multicentre prospective survey. Am. J. Hematol. 2016, 91, 1076-1081. [CrossRef] [PubMed]

16. Puerta-Alcalde, P.; Cardozo, C.; Marco, F.; Suárez-Lledó, M.; Moreno, E.; Morata, L.; Fernández-Avilés, F.; Gutiérrez-Garcia, G.; Chumbita, M.; Rosiñol, L.; et al. Changing epidemiology of bloodstream infection in a 25-years hematopoietic stem cell transplant program: Current challenges and pitfalls on empiric antibiotic treatment impacting outcomes. Bone Marrow Transplant. 2020, 55, 603-612. [CrossRef]

17. Girmenia, C.; Rossolini, G.M.; Piciocchi, A.; Bertaina, A.; Pisapia, G.; Pastore, D.; Sica, S.; Severino, A.; Cudillo, L.; Ciceri, F.; et al. Infections by carbapenem-resistant Klebsiella pneumoniae in SCT recipients: A nationwide retrospective survey from Italy. Bone Marrow Transplant. 2015, 50, 282-288. [CrossRef]

18. Girmenia, C.; Bertaina, A.; Piciocchi, A.; Perruccio, K.; Algarotti, A.; Busca, A.; Cattaneo, C.; Raiola, A.M.; Guidi, S.; Iori, A.P.; et al. Incidence, Risk Factors and Outcome of Pre-engraftment Gram-Negative Bacteremia After Allogeneic and Autologous Hematopoietic Stem Cell Transplantation: An Italian Prospective Multicenter Survey. Clin. Infect. Dis. 2017, 65, 1884-1896. [CrossRef]

19. Gafter-Gvili, A.; Fraser, A.; Paul, M.; Vidal, L.; Lawrie, T.A.; Van De Wetering, M.D.; Kremer, L.C.M.; Leibovici, L. Antibiotic prophylaxis for bacterial infections in afebrile neutropenic patients following chemotherapy. Cochrane Database Syst. Rev. 2012, 2012, CD004386. [CrossRef]

20. Kern, W.V.; Weber, S.; Dettenkofer, M.; Kaier, K.; Bertz, H.; Behnke, M.; Weisser, M.; Götting, T.; Widmer, A.F.; Theilacker, C. Impact of fluoroquinolone prophylaxis during neutropenia on bloodstream infection: Data from a surveillance program in 8755 patients receiving high-dose chemotherapy for haematologic malignancies between 2009 and 2014. J. Infect. 2018, 77, 68-74. [CrossRef]

21. Owattanapanich, W.; Chayakulkeeree, M. Efficacy of levofloxacin as an antibacterial prophylaxis for acute leukemia patients receiving intensive chemotherapy: A systematic review and meta-analysis. Hematology 2019, 24, 362-368. [CrossRef] [PubMed] 
22. Kimura, S.-I.; Akahoshi, Y.; Nakano, H.; Ugai, T.; Wada, H.; Yamasaki, R.; Ishihara, Y.; Kawamura, K.; Sakamoto, K.; Ashizawa, M.; et al. Antibiotic prophylaxis in hematopoietic stem cell transplantation. A meta-analysis of randomized controlled trials. J. Infect. 2014, 69, 13-25. [CrossRef] [PubMed]

23. Taplitz, R.A.; Kennedy, E.B.; Bow, E.J.; Crews, J.; Gleason, C.; Hawley, D.K.; Langston, A.A.; Nastoupil, L.J.; Rajotte, M.; Rolston, K.V.; et al. Antimicrobial prophylaxis for adult patients with cancer-related immunosuppression: ASCO and IDSA clinical practice guideline update. JCO 2018, 36, 3043-3054. [CrossRef] [PubMed]

24. Ullmann, A.J.; On behalf of the Infectious Diseases Working Party of the German Society for Hematology and Medical Oncology (AGIHO/DGHO) and the DAG-KBT (German Working Group for Blood and Marrow Transplantation); Schmidt-Hieber, M.; Bertz, H.; Heinz, W.J.; Kiehl, M.; Krüger, W.; Mousset, S.; Neuburger, S.; Neumann, S.; et al. Infectious diseases in allogeneic haematopoietic stem cell transplantation: Prevention and prophylaxis strategy guidelines 2016. Ann. Hematol. 2016, 95, 1435-1455. [CrossRef]

25. Kochanek, M.; Schalk, E.; von Bergwelt-Baildon, M.; Beutel, G.; Buchheidt, D.; Hentrich, M.; Henze, L.; Kiehl, M.; Liebregts, T.; von Lilienfeld-Toal, M.; et al. Management of sepsis in neutropenic cancer patients: 2018 guidelines from the Infectious Diseases Working Party (AGIHO) and Intensive Care Working Party (iCHOP) of the German Society of Hematology and Medical Oncology (DGHO). Ann. Hematol. 2019, 98, 1051-1069. [CrossRef]

26. Rhodes, A.; Evans, L.E.; Alhazzani, W.; Levy, M.M.; Antonelli, M.; Ferrer, R.; Kumar, A.; Sevransky, J.E.; Sprung, C.L.; Nunnally, M.E.; et al. Surviving Sepsis Campaign: International Guidelines for Management of Sepsis and Septic Shock: 2016. Intensive Care Med. 2017, 43, 304-377. [CrossRef]

27. Cecconi, M.; Evans, L.; Levy, M.; Rhodes, A. Sepsis and septic shock. Lancet 2018, 392, 75-87. [CrossRef]

28. Levy, M.M.; Evans, L.E.; Rhodes, A. The Surviving Sepsis Campaign Bundle: 2018 Update. Crit. Care Med. 2018, 46, 997-1000. [CrossRef]

29. Singer, M.; Deutschman, C.S.; Seymour, C.W.; Shankar-Hari, M.; Annane, D.; Bauer, M.; Bellomo, R.; Bernard, G.R.; Chiche, J.D.; Coopersmith, C.M.; et al. The Third International Consensus Definitions for Sepsis and Septic Shock (Sepsis-3). JAMA 2016, 315, 801-810. [CrossRef]

30. Nathan, N.; Sculier, J.P.; Ameye, L.; Paesmans, M.; Bogdan-Dragos, G.; Meert, A.P. Sepsis and Septic Shock Definitions in Patients with Cancer Admitted in ICU. J. Intensive Care Med. 2019, 23, 0885066619894933. [CrossRef]

31. Hansen, B.A.; Wendelbo, Ø.; Bruserud, Ø.; Hemsing, A.L.; Mosevoll, K.A.; Reikvam, H. Febrile Neutropenia in Acute Leukemia. Epidemiology, Etiology, Pathophysiology and Treatment. Mediterr. J. Hematol. Infect. Dis. 2020, 12, e2020009. [CrossRef] [PubMed]

32. Averbuch, D.; Orasch, C.; Cordonnier, C.; Livermore, D.M.; Mikulska, M.; Viscoli, C.; Gyssens, I.C.; Kern, W.V.; Klyasova, G.; Marchetti, O.; et al. European guidelines for empirical antibacterial therapy for febrile neutropenic patients in the era of growing resistance: Summary of the 2011 th European Conference on Infections in Leukemia. Haematologica 2013, 98, 1826-1835. [CrossRef] [PubMed]

33. Averbuch, D.; Cordonnier, C.; Livermore, D.M.; Mikulska, M.; Orasch, C.; Viscoli, C.; Gyssens, I.C.; Kern, W.V.; Klyasova, G.; Marchetti, O.; et al. Targeted therapy against multi-resistant bacteria in leukemic and hematopoietic stem cell transplant recipients: Guidelines of the 4th European Conference on Infections in Leukemia (ECIL-4, 2011). Haematologica 2013, 98, 1836-1847. [CrossRef]

34. Scheich, S.; Weber, S.; Reinheimer, C.; Wichelhaus, T.A.; Hogardt, M.; Kempf, V.A.J.; Kessel, J.; Serve, H.; Steffen, B. Bloodstream infections with gram-negative organisms and the impact of multidrug resistance in patients with hematological malignancies. Ann. Hematol. 2018, 97, 2225-2234. [CrossRef]

35. Gudiol, C.; Tubau, F.; Calatayud, L.; Garcia-Vidal, C.; Cisnal, M.; Sánchez-Ortega, I.; Duarte, R.; Calvo, M.; Carratalà, J. Bacteraemia due to multidrug-resistant Gram-negative bacilli in cancer patients: Risk factors, antibiotic therapy and outcomes. J. Antimicrob. Chemother. 2011, 66, 657-663. [CrossRef]

36. Freifeld, A.G.; Bow, E.J.; Sepkowitz, K.A.; Boeckh, M.J.; Ito, J.I.; Mullen, C.A.; Raad, I.I.; Rolston, K.V.; Young, J.A.; Wingard, J.R. Clinical practice guideline for the use of antimicrobial agents in neutropenic patients with cancer: 2010 update by the infectious diseases society of america. Clin. Infect. Dis. 2011, 52, 56-93. [CrossRef] 
37. Harris, P.N.A.; Tambyah, P.A.; Lye, D.C.; Mo, Y.; Lee, T.H.; Yilmaz, M.; Alenazi, T.H.; Arabi, Y.; Falcone, M.; Bassetti, M.; et al. Effect of Piperacillin-Tazobactam vs Meropenem on 30-Day Mortality for Patients With E coli or Klebsiella pneumoniae Bloodstream Infection and Ceftriaxone Resistance: A Randomized Clinical Trial. JAMA 2018, 320, 984-994. [CrossRef]

38. Snyder, M.; Pasikhova, Y.; Baluch, A. Early Antimicrobial De-escalation and Stewardship in Adult Hematopoietic Stem Cell Transplantation Recipients: Retrospective Review. Open Forum Infect. Dis. 2017, 4, ofx226. [CrossRef]

39. Gustinetti, G.; Raiola, A.M.; Varaldo, R.; Galaverna, F.; Gualandi, F.; Del Bono, V.; Bacigalupo, A.; Angelucci, E.; Viscoli, C.; Mikulska, M. De-Escalation and Discontinuation of Empirical Antibiotic Treatment in a Cohort of Allogeneic Hematopoietic Stem Cell Transplantation Recipients during the Pre-Engraftment Period. Biol. Blood Marrow Transplant. 2018, 24, 1721-1726. [CrossRef]

40. Mokart, D.; Slehofer, G.; Lambert, J.; Sannini, A.; Chow-Chine, L.; Brun, J.P.; Berger, P.; Duran, S.; Faucher, M.; Blache, J.L.; et al. De-escalation of antimicrobial treatment in neutropenic patients with severe sepsis: Results from an observational study. Intensive Care Med. 2014, 40, 41-49. [CrossRef]

41. Gutiérrez-Gutiérrez, B.; Salamanca, E.; de Cueto, M.; Hsueh, P.R.; Viale, P.; Paño-Pardo, J.R.; Venditti, M.; Tumbarello, M.; Daikos, G.; Cantón, R.; et al. Effect of appropriate combination therapy on mortality of patients with bloodstream infections due to carbapenemase-producing Enterobacteriaceae (INCREMENT): A retrospective cohort study. Lancet Infect. Dis. 2017, 17, 726-734. [CrossRef]

42. Paul, M.; Soares-Weiser, K.; Leibovici, L. Beta lactam monotherapy versus beta lactam-aminoglycoside combination therapy for fever with neutropenia: Systematic review and meta-analysis. BMJ 2003, 326, 1111. [CrossRef] [PubMed]

43. Kumar, A.; Zarychanski, R.; Light, B.; Parrillo, J.; Maki, D.; Simon, D.; Laporta, D.; Lapinsky, S.; Ellis, P.; Mirzanejad, Y.; et al. Early combination antibiotic therapy yields improved survival compared with monotherapy in septic shock: A propensity-matched analysis. Crit. Care Med. 2010, 38, 1773-1785. [CrossRef] [PubMed]

44. René, L.; Rello, J.; Silvio, T.F.; Salem, O.B.H.; Bauer, P.R.; Séguin, A.; van de Louw, A.; Metaxa, V.; Klouche, K.; Ignacio, M.L.; et al. Aminoglycosides in Immunocompromised Critically Ill Patients with Bacterial Pneumonia and Septic Shock: A Post-Hoc Analysis of a Prospective Multicenter Multinational Cohort. Shock 2020, 2. [CrossRef]

45. Rello, J.; Sarda, C.; Mokart, D.; Arvaniti, K.; Akova, M.; Tabah, A.; Azoulay, E. Antimicrobial Stewardship in Hematological Patients at the intensive care unit: A global cross-sectional survey from the Nine-i Investigators Network. Eur. J. Clin. Microbiol. Infect. Dis. 2020, 39, 385-392. [CrossRef]

46. Legrand, M.; Max, A.; Schlemmer, B.; Azoulay, E.; Gachot, B. The strategy of antibiotic use in critically ill neutropenic patients. Ann. Intensive Care 2011, 1, 2110-5820. [CrossRef]

47. Vossen, M.G.; Milacek, C.; Thalhammer, F. Empirical antimicrobial treatment in haemato-/oncological patients with neutropenic sepsis. ESMO Open 2018, 3, e000348. [CrossRef]

48. Wilson, H.; Török, M.E. Extended-spectrum b-lactamase-producing and carbapenemase-producing Enterobacteriaceae. Microb. Genom. 2018, 4. [CrossRef]

49. Porreca, A.M.; Sullivan, K.V.; Gallagher, J.C. The epidemiology, evolution, and treatment of KPC-producing organisms. Curr. Infect. Dis. Rep. 2018, 20,13. [CrossRef]

50. Bush, K. Past and present perspectives on $\beta$-lactamases. Antimicrob. Agents Chemother. 2018, 62, e01076-18. [CrossRef]

51. Walsh, T.R. The emergence and implications of metallo-beta-lactamases in Gram-negative bacteria. Clin. Microbiol. Infect. 2005, 11 (Suppl. 6), 2-9. [CrossRef] [PubMed]

52. Walsh, T.R.; Toleman, M.A.; Poirel, L.; Nordmann, P. Metallo-beta-lactamases: The quiet before the storm? Clin. Microbiol. Rev. 2005, 18, 306-325. [CrossRef] [PubMed]

53. Jacoby, G.A. AmpC $\beta$-Lactamases. Clin. Microbiol. Rev. 2009, 22, 161-182. [CrossRef] [PubMed]

54. Zhanel, G.G.; Lawrence, C.K.; Adam, H.; Schweizer, F.; Zelenitsky, S.; Zhanel, M.; Lagacé-Wiens, P.R.S.; Walkty, A.; Denisuik, A.; Golden, A.; et al. Imipenem-relebactam and meropenem-vaborbactam: Two novel carbapenem-b-lactamase inhibitor combinations. Drugs 2018, 78, 65-98. [CrossRef] 
55. Bidair, M.; Zervos, M.; Sagan, O.S.; Zaitsev, V.; Loutit, J.S.; Dudley, M.N.; Vazquez, V. Clinical outcomes in adults with complicated urinary tract infections (cUTI), including acute pyelonephritis (AP) in TANGO 1, a phase 3 randomized, double-blind, double-dummy trial comparing meropenem-vaborbactam $(\mathrm{M}-\mathrm{V})$ with piperacillin-tazobactam (PT) [abstract no. P1289 plus poster]. In Proceedings of the 27th European Congress of Clinical Microbiology and Infectious Diseases, Vienna, Austria, 22-25 April 2007.

56. Kaye, K.S.; Vazquez, J.; Mathers, A.; Daikos, G.; Alexander, E.; Loutit, J.S.; Zhang, S.; Dudley, M.N.; Cornely, O. Clinical outcomes of serious infections due to carbapenem-resistant enterobacteriaceae (CRE) in TANGO II a phase 3 randomized multinational open-label trial of meropenem-vaborbactam (MV) versus best available therapy (BAT). [abstract no. 1862]. In Proceedings of the IDWeek, San Diego, CA, USA, 4-8 October 2017.

57. A Study of Meropenem-Vaborbactam Versus Piperacillin/Tazobactam in Participants with Hospital-Acquired and Ventilator-Associated Bacterial Pneumonia (TANGOIII), Clinicaltrials.gov, NCT02687906. Available online: https://clinicaltrials.gov/ct2/show/NCT03006679 (accessed on 10 November 2020).

58. Lucasti, C.; Vasile, L.; Sandesc, D.; Venskutonis, D.; McLeroth, P.; Lala, M.; Rizk, M.L.; Brown, M.L.; Losada, M.C.; Pedley, A.; et al. Phase 2, dose-ranging study of relebactam with imipenem-cilastatin in subjects with complicated intra-abdominal infection. Antimicrob. Agents Chemother. 2016, 60, 6234-6243. [CrossRef]

59. Motsch, J.; de Oliveira, C.; Stus, V.; Köksal, I.; Lyulko, O.; Boucher, H.W.; Kaye, K.S.; File, T.M.; Brown, M.L.; Khan, I. RESTORE-IMI 1: A multicenter, randomized, double-blind, comparator-controlled trial comparing the efficacy and safety of imipenem/relebactam versus colistin plus imipenem in patients with imipenem nonsusceptible bacterial infections. In Proceedings of the 28th European Congress of Clinical Microbiology and Infectious Diseases (ECCMID), Madrid, Spain, 21-24 April 2018.

60. Imipenem/Relebactam/Cilastatin Versus Piperacillin/Tazobactam for Treatment of Participants with Bacterial Pneumonia (MK-7655A-014) (RESTORE-IMI 2), Clinicaltrial.gov, NCT02493764. Available online: https: //clinicaltrials.gov/ct2/show/NCT02493764 (accessed on 10 November 2020).

61. Bassetti, M.; Ariyasu, M.; Binkowitz, B.; Nagata, T.D.; Echols, R.M.; Matsunaga, Y.; Toyoizumi, K.; Doi, Y. Designing A Pathogen-Focused Study to Address the High Unmet Medical Need Represented By Carbapenem-Resistant Gram-Negative Pathogens-The International, Multicenter, Randomized, Open-Label, Phase 3 CREDIBLE-CR Study. Infect. Drug Resist. 2019, 12, 3607-3623. [CrossRef]

62. Echols, R.; Ariyasu, M.; Nagata, T.D. Pathogen-focused Clinical Development to Address Unmet Medical Need: Cefiderocol Targeting Carbapenem Resistance. Clin. Infect. Dis. 2019, 69, S559-S564. [CrossRef]

63. Hsueh, S.C.; Lee, Y.J.; Huang, Y.T.; Liao, C.H.; Tsuji, M.; Hsueh, P.R. In vitro activities of cefiderocol, ceftolozane/tazobactam, ceftazidime/avibactam and other comparative drugs against imipenem-resistant Pseudomonas aeruginosa and Acinetobacter baumannii, and Stenotrophomonas maltophilia, all associated with bloodstream infections in Taiwan. J. Antimicrob. Chemother. 2019, 74, 380-386.

64. Gudiol, C.; Cuervo, G.; Carratalà, J. Optimizing therapy of bloodstream infection due to extended-spectrum $\beta$-lactamase-producing Enterobacteriaceae. Curr. Opin. Crit. Care 2019, 25, 438-448. [CrossRef]

65. Voulgaris, G.L.; Voulgari, M.L.; Falagas, M.E. Developments on antibiotics for multidrug resistant bacterial Gram-negative infections. Expert Rev. Anti-Infect. Ther. 2019, 17, 387-401. [CrossRef]

66. Van de Wyngaert, Z.; Berthon, C.; Debarri, H.; Bories, C.; Bonnet, S.; Nudel, M.; Carpentier, B.; Legrand, C.; Barbieux, S.; Chauvet, P.; et al. Discontinuation of antimicrobial therapy in adult neutropenic haematology patients: A prospective cohort. Int. J. Antimicrob. Agents 2019, 53, 781-788. [CrossRef] [PubMed]

67. Aguilar-Guisado, M.; Espigado, I.; Martín-Peña, A.; Gudiol, C.; Royo-Cebrecos, C.; Falantes, J.; Vázquez-López, L.; Montero, M.I.; Rosso-Fernández, C.; de la Luz Martino, M.; et al. Optimisation of empirical antimicrobial therapy in patients with haematological malignancies and febrile neutropenia (How Long study): An open-label, randomised, controlled phase 4 trial. Lancet Haematol. 2017, 4, e573-e583. [CrossRef]

68. Schmidt-Hieber, M.; Teschner, D.; Maschmeyer, G.; Schalk, E. Management of febrile neutropenia in the perspective of antimicrobial de-escalation and discontinuation. Expert Rev. Anti-Infect. Ther. 2019, 17, 983-995. [CrossRef] [PubMed]

69. Verlinden, A.; Mikulska, M.; Knelange, N.S.; Averbuch, D.; Styczynski, J. Current antimicrobial practice in febrile neutropenia across Europe and Asia: The EBMT Infectious Disease Working Party survey. Bone Marrow Transplant. 2020, 55, 1588-1594. [CrossRef] [PubMed] 
70. Legrand, M.; Max, A.; Peigne, V.; Mariotte, E.; Canet, E.; Debrumetz, A.; Lemiale, V.; Seguin, A.; Darmon, M.; Schlemmer, B.; et al. Survival in neutropenic patients with severe sepsis or septic shock. Crit. Care Med. 2012, 40, 43-49. [CrossRef] [PubMed]

71. Azoulay, E.; Mokart, D.; Pène, F.; Lambert, J.; Kouatchet, A.; Mayaux, J.; Vincent, F.; Nyunga, M.; Bruneel, F.; Laisne, L.M.; et al. Outcomes of critically ill patients with hematologic malignancies: Prospective multicenter data from France and Belgium-a groupe de recherche respiratoire en réanimation onco-hématologique study. J. Clin. Oncol. 2013, 31, 2810-2818. [CrossRef] [PubMed]

72. Mokart, D.; Lambert, J.; Schnell, D.; Fouché, L.; Rabbat, A.; Kouatchet, A.; Lemiale, V.; Vincent, F.; Lengliné, E.; Bruneel, F.; et al. Delayed intensive care unit admission is associated with increased mortality in patients with cancer with acute respiratory failure. Leuk. Lymphoma 2013, 54, 1724-1729. [CrossRef]

73. Azoulay, E.; Schellongowski, P.; Darmon, M.; Bauer, P.R.; Benoit, D.; Depuydt, P.; Divatia, J.V.; Lemiale, V.; van Vliet, M.; Meert, A.P.; et al. The Intensive Care Medicine research agenda on critically ill oncology and hematology patients. Intensive Care Med. 2017, 43, 1366-1382. [CrossRef]

74. Azoulay, E.; Pène, F.; Darmon, M.; Lengliné, E.; Benoit, D.; Soares, M.; Vincent, F.; Bruneel, F.; Perez, P.; Lemiale, V.; et al. Managing critically Ill hematology patients: Time to think differently. Blood Rev. 2015, 29, 359-367. [CrossRef]

75. Peyrony, O.; Chevret, S.; Meert, A.P.; Perez, P.; Kouatchet, A.; Pène, F.; Mokart, D.; Lemiale, V.; Demoule, A.; Nyunga, M.; et al. Direct admission to the intensive care unit from the emergency department and mortality in critically ill hematology patients. Ann. Intensive Care 2019, 9, 110. [CrossRef]

76. Shimabukuro-Vornhagen, A.; Böll, B.; Kochanek, M.; Azoulay, É.; von Bergwelt-Baildon, M.S. Critical care of patients with cancer. CA Cancer J. Clin. 2016, 66, 496-517. [CrossRef] [PubMed]

77. Wise, M.P.; Barnes, R.A.; Baudouin, S.V.; Howell, D.; Lyttelton, M.; Marks, D.I.; Morris, E.C.; Parry-Jones, N. Guidelines on the management and admission to intensive care of critically ill adult patients with haematological malignancy in the UK. Br. J. Haematol. 2015, 171, 179-188. [CrossRef] [PubMed]

78. Lengliné, E.; Mirouse, A.; Azoulay, E. Top ten tips for the management of critically ill hematopoietic stem cell transplantation recipients. Intensive Care Med. 2019, 45, 384-387. [CrossRef] [PubMed]

79. Lemiale, V.; Pons, S.; Mirouse, A.; Tudesq, J.J.; Hourmant, Y.; Mokart, D.; Pène, F.; Kouatchet, A.; Mayaux, J.; Nyunga, M.; et al. Sepsis and Septic Shock in Patients With Malignancies: A Groupe de Recherche Respiratoire en Réanimation Onco-Hématologique Study. Crit. Care Med. 2020, 48, 822-829. [CrossRef] [PubMed]

80. Bouteloup, M.; Perinel, S.; Bourmaud, A.; Azoulay, E.; Mokart, D.; Darmon, M. Outcomes in adult critically ill cancer patients with and without neutropenia: A systematic review and meta-analysis of the Groupe de Recherche en Réanimation Respiratoire du patient d'Onco-Hématologie (GRRR-OH). Oncotarget 2017, 8, 1860-1870. [CrossRef] [PubMed]

81. Saillard, C.; Darmon, M.; Bisbal, M.; Sannini, A.; Chow-Chine, L.; Faucher, M.; Lengline, E.; Vey, N.; Blaise, D.; Azoulay, E.; et al. Critically ill allogenic HSCT patients in the intensive care unit: A systematic review and meta-analysis of prognostic factors of mortality. Bone Marrow Transplant. 2018, 53, 1233-1241. [CrossRef] [PubMed]

Publisher's Note: MDPI stays neutral with regard to jurisdictional claims in published maps and institutional affiliations.

(C) 2020 by the authors. Licensee MDPI, Basel, Switzerland. This article is an open access article distributed under the terms and conditions of the Creative Commons Attribution (CC BY) license (http://creativecommons.org/licenses/by/4.0/). 